\title{
Comparison of the Assessment of Orthostatic Hypotension Using Peripheral and Central Blood Pressure Measurements
}

\author{
Kannayiram Alagiakrishnan ${ }^{\mathrm{a}, \mathrm{d}}$, Ruojin Bu ${ }^{\mathrm{b}}$, Peter Hamilton ${ }^{\mathrm{b}}$, \\ Ambikaipakan Senthilselvanc, Raj Padwal ${ }^{\mathrm{b}}$
}

\begin{abstract}
Background: Orthostatic hypotension $(\mathrm{OH})$ is associated with falls and cardiovascular events. There is growing evidence that central blood pressure (CBP) is better than peripheral blood pressure (PBP) in predicting adverse outcomes. The objectives of this study were to assess 1) the prevalence of $\mathrm{OH}$ identified using PBP and CBP and the levels of agreement, 2) the respective associations between $\mathrm{OH}$ and falls and cardiovascular comorbidities, by PBP and CBP, and 3) the association of $\mathrm{OH}$ with arterial wall stiffness markers (augmentation pressure (AP) and augmentation index (AI)).
\end{abstract}

Methods: An observational case-control study of subjects aged 50 years and above was conducted at the University of Alberta Hospital inpatient wards and outpatient clinics. This study used a non-invasive technology called SphygmoCor to assess changes in CBP between lying, 1, 3 and 6 min of standing. AP and AI, which are markers of arterial wall stiffness, were also measured in this study. Dementia, significant psychological problems, and isolation precautions were exclusion criteria. Both PBP and CBP were measured with arm cuffs in lying and standing positions. $\mathrm{OH}$ was diagnosed using consensus criteria.

Results: Of the 71 participants recruited, mean age was $72.3 \pm 10.3$ years, $52 \%$ were males, $32 \%$ had a history of falls and $72 \%$ had hypertension. $\mathrm{OH}$ occurred within 1, 3 or 6 min of standing (transient $\mathrm{OH})$ in $31 \%$ by $\mathrm{PBP}$ and $27 \%$ by $\mathrm{CBP}(\mathrm{kappa}=0.56)$. OH persisted for all 6 min (persistent $\mathrm{OH}$ ) in 16\% by both PBP and CBP (kappa $=$ 0.68). A significant relationship was observed between transient $\mathrm{OH}$ by $\mathrm{CBP}$ and baseline hypertension $(\mathrm{P}=0.05)$ and dyslipidemia ( $\mathrm{P}$ $=0.02)$. There was a significant difference in the mean AP between subjects with and without central persistent $\mathrm{OH}(\mathrm{P}=0.02)$, but not between subjects with and without peripheral persistent $\mathrm{OH}$. The mean AI was not significantly different between subjects with or without

Manuscript submitted January 4, 2018, accepted January 29, 2018

aDivision of Geriatric Medicine, Department of Medicine, University of Alberta, Edmonton, Canada

${ }^{b}$ Department of Medicine, University of Alberta, Edmonton, Canada ${ }^{\mathrm{c} S}$ School of Public Health, University of Alberta, Edmonton, Canada

${ }^{\mathrm{d}}$ Corresponding Author: Kannayiram Alagiakrishnan, Clinical Sciences Building, University of Alberta Hospital, 8440-112St, Edmonton, AB T6G 2G3, Canada. Email: KAlagiakri@aol.com

doi: https://doi.org/10.14740/jocmr3353w central or peripheral persistent $\mathrm{OH}$ and between subjects with and without peripheral or central transient $\mathrm{OH}$.

Conclusion: Prevalence of $\mathrm{OH}$ was similar between PBP and CBP. However, there was only moderate agreement with $\mathrm{OH}$ identified by PBP and CBP indicating some inconsistencies across the sample in identifying $\mathrm{OH}$.

Keywords: Orthostatic hypotension; Central blood pressure; Peripheral blood pressure; Aortic stiffness

\section{Introduction}

An accurate measurement of blood pressure (BP) and postural changes is essential to plan therapy in the elderly. Automated oscillometric devices are available and are widely used for home blood pressure monitoring (HBPM), 24-h ambulatory blood pressure monitoring and in-office monitoring. Recent innovations enable these devices to measure central blood pressure (CBP) non-invasively. In many individuals, peripheral blood pressure (PBP) measured over the brachial artery differs from aortic CBP measured through novel non-invasive techniques. Although brachial PBP has long been used clinically as the standard method of blood pressure measurement, there is growing evidence to suggest that CBP has incremental ability over PBP in predicting target organ damage and cardiovascular (CV) events [1].

Orthostatic or postural hypotension $(\mathrm{OH} / \mathrm{PH})$ is a common, under-recognized disabling condition [2]. In this condition, subjects experience a systolic blood pressure (SBP) drop of $20 \mathrm{~mm} \mathrm{Hg}$ or more, or a diastolic blood pressure (DBP) drop of $10 \mathrm{~mm} \mathrm{Hg}$ or more, with or without an increase in heart or pulse rate, with or without symptoms, and within 3 min after standing [3]. If this BP drop occurs at $6 \mathrm{~min}$, it is called delayed $\mathrm{OH} / \mathrm{PH}$ [4]. $\mathrm{OH} / \mathrm{PH}$ is associated with an increased incidence of morbidities (falls, CV issues and cognitive decline) and mortality [5]. However, there is some uncertainty over the diagnostic criteria using $\mathrm{CBP}$ for $\mathrm{OH} / \mathrm{PH}$ in patients with and without hypertension. Our hypothesis is CBP will be good in measuring $\mathrm{OH}$ and predicting its relevant outcomes. The objectives of this study were 1) to assess the prevalence of $\mathrm{OH} / \mathrm{PH}$ using PBP and $\mathrm{CBP}, 2)$ to assess whether the respective association between $\mathrm{OH} / \mathrm{PH}$ and falls, $\mathrm{OH} / \mathrm{PH}$ and $\mathrm{CV}$ 
Table 1. Baseline Characteristics of Hypertensive and Normotensive Groups

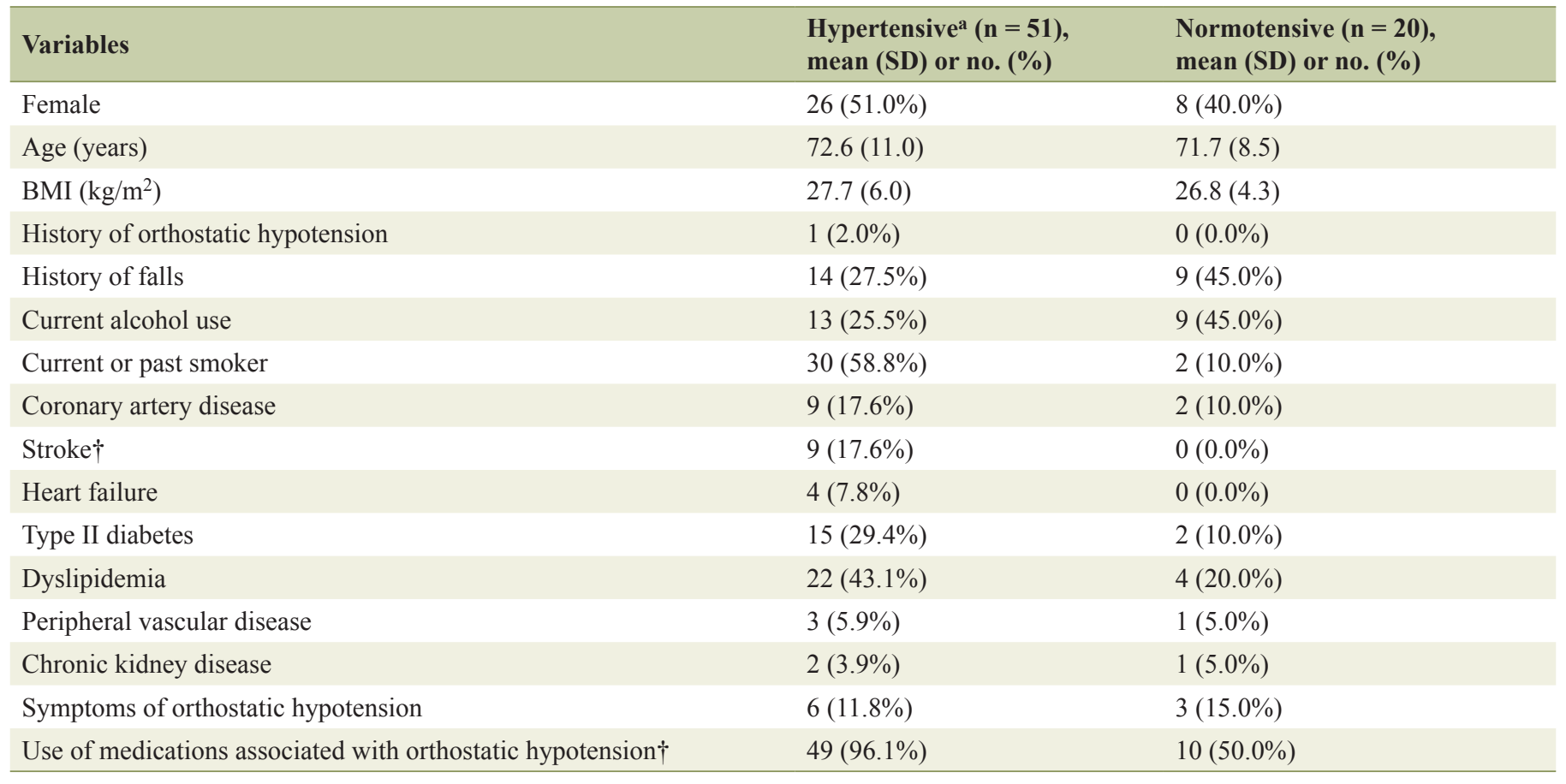

aObtained from medical records. $† P<0.05$.

comorbidities, is stronger by $\mathrm{CBP}$ or PBP, and 3) to assess the association of $\mathrm{OH}$ with arterial wall stiffness markers (augmentation pressure (AP) and augmentation index (AI)), as the alteration of the reflection pressure wave due to arterial wall stiffness could be one of the underlying mechanisms of $\mathrm{OH}$ in the central artery.

\section{Methodology}

An observational case-control study was conducted over a 3-month period at the University of Alberta Hospital in Edmonton, Canada and included a convenience sample of 71 normotensive and hypertensive subjects from both inpatient wards and outpatient clinics. Each patient provided informed written consent. Inclusion criteria were age of 50 years or greater with a diagnosis of hypertension (or controls without hypertension) who were willing to participate in the study and were able to stand with or without a walking aid. Subjects who did not speak English, had a history of dementia, blindness, anxiety or significant psychological problems including schizophrenia, substance abuse, pain, medically unstable, terminal illness, who were on infection precautions or not able to consent for the study were excluded.

BP measurements were taken using a SphygmoCor device. Estimated CBP indices included central SBP, central DBP and pulse pressure. AI and AP, which are arterial wall stiffness parameters, were also measured. $\mathrm{PBP}$ was measured with regular BP cuffs over the brachial artery, in both supine and standing positions. First, PBP was measured in the supine position twice after 10 min of rest. Following this, PBP was measured at 1, 3 and 6 min of standing, twice for each interval. After the completion of PBP measurements, the CBP measurements were taken. Using the non-invasive SphygmoCor system, CBP was measured twice in the supine position, twice on intervals of 1, 3, and 6 min of standing, and the average of these two readings were taken. The calibrated SphygmorCor system began by measuring PBP, then switched to measure CBP, using the aortic pressure waveform estimated by a validated transfer function [6]. CBP indices, AP and AI, were also generated from this waveform. For the purpose of this study, transient $\mathrm{OH}$ was defined as a drop in BP meeting $\mathrm{OH}$ criteria (listed above) in the standing position at 1 or 3 or $6 \mathrm{~min}$. Persistent $\mathrm{OH}$ was defined as a drop in BP at all the three time points 1, 3 and $6 \mathrm{~min}$.

Demographic variables (age and sex), vascular risk factors (type 2 diabetes, hypertension, dyslipidemia, smoking, coronary artery disease, heart failure, cerebrovascular disease, peripheral vascular disease, and renal failure), history of dementia, depression and other mental illnesses, history of falls, and current medications were collected. Comorbidities were delineated from self-report and review of medical records. The presence of $\mathrm{OH} / \mathrm{PH}$ related symptoms was also collected.

The outcomes of this study were 1) the prevalence of $\mathrm{OH} /$ $\mathrm{PH}$ by $\mathrm{CBP}$ and PBP measurements, 2) the association between comorbidities and $\mathrm{OH} / \mathrm{PH}, 3$ ) the agreement between $\mathrm{OH} / \mathrm{PH}$ by CBP and PBP measurements, and 4) the association between transient $\mathrm{OH}$ and persistent $\mathrm{OH}$ with $\mathrm{CV}$ outcomes and falls.

Ethics approval was obtained from the University of Alberta Health Research Ethics Board and operations/adminis- 
Table 2. Prevalence and Agreement of Orthostatic Hypotension $(\mathrm{OH})$ by Peripheral and Central Blood Pressures and by Types of Orthostatic Hypotensiona

\begin{tabular}{|c|c|c|c|}
\hline Types of $\mathrm{OH}$ & $\begin{array}{l}\text { Peripheral blood pressure } \\
(\mathrm{n}=71), \text { no. }(\%)\end{array}$ & $\begin{array}{l}\text { Central blood pressure } \\
(\mathrm{n}=71), \text { no. }(\%)\end{array}$ & $\begin{array}{l}\text { Agreement } \\
\left(\text { kappa }^{b}\right)\end{array}$ \\
\hline Early OH & $12(16.9 \%)$ & $17(23.9 \%)$ & 0.70 \\
\hline Delayed $\mathrm{OH}$ & $18(25.4 \%)$ & $14(19.7 \%)$ & 0.44 \\
\hline Transient $\mathrm{OH}$ & $22(31.0 \%)$ & $19(26.8 \%)$ & 0.56 \\
\hline
\end{tabular}

aEarly $\mathrm{OH}$ : at $1 \mathrm{~min}$ of standing; $\mathrm{OH}$ : at $3 \mathrm{~min}$ of standing; delayed $\mathrm{OH}$ : at 6 min of standing; transient $\mathrm{OH}$ : at 1 or 3 or 6 min of standing; persistent $\mathrm{OH}$ : seen at 1, 3, and 6 min of standing. 'bleiss's guidelines (Fleiss et al, 2003) characterize kappa $>0.75$ as excellent, $0.40-0.75$ as good, $<0.40$ as poor.

trative approval was obtained from Alberta Health Services.

\section{Statistical analysis}

Descriptive statistics were reported for all demographic and clinical parameters. The prevalence of $\mathrm{OH} / \mathrm{PH}$ was described for the study sample. Baseline patient characteristics and clinical outcomes were reported according to the presence and absence of hypertension. Percentages were used to describe discrete variables, and medians with 25 th and 75 th percentiles were used to describe continuous variables. Differences in the means of continuous variables were tested by Student's $t$-tests or Mann-Whitney U tests. Differences in proportions were tested by Chi-square or Fisher's exact tests. Multiple logistic regression analysis was conducted to examine the association between the dichotomized morbidities and $\mathrm{OH} / \mathrm{PH}$ using $\mathrm{CBP}$ and PBP after controlling for potential confounders. Age was dichotomized into $\leq 65$ years and $>65$ years. Statistical analysis was performed using STATA. A P-value of $<0.05$ was considered as statistically significant.

\section{Results}

Among the 71 participants, the mean age was $72.3 \pm 10.3$ years, $52 \%$ were males, $32 \%$ had a history of falls and $72 \%$ had hypertension (Table 1). Of these with hypertension, 12 subjects $(6 \%)$ exhibited symptomatic $\mathrm{OH}$ during the assessment. There was a statistically significant association between symptoms and age group $(\mathrm{P}=0.01)$ but not with sex. No significant association between $\mathrm{OH}$ and the number of drugs used or causative drug use was found.

Using the consensus statement on the definition of $\mathrm{OH}$, $\mathrm{OH}$ was identified at 1, 3 or 6 min of standing (transient $\mathrm{OH}$ ) in $31 \%$ by $\mathrm{PBP}$ and $27 \%$ by CBP with a moderate agreement $(\mathrm{kappa}=0.56)$ and across all durations (persistent $\mathrm{OH})$ in $16 \%$ by both PBP and CBP with a stronger agreement (kappa = 0.68) (Table 2).

A significant relationship was observed between transient $\mathrm{OH}$ as measured by $\mathrm{CBP}$ and having hypertension $(\mathrm{P}=0.05)$ and dyslipidemia $(\mathrm{P}=0.02)$, but the association was not significant with other $\mathrm{CV}$ risk factors. There was a significant difference in the mean AP between subjects with and without central persistent $\mathrm{OH}(\mathrm{P}=0.02)$, but not between subjects with and without peripheral persistent $\mathrm{OH}$. The mean AI was not significantly different between subjects with or without central or peripheral persistent $\mathrm{OH}$ and between subjects with and without peripheral or central transient $\mathrm{OH}$. In this study, transient $\mathrm{OH}$ was associated with past falls $(\mathrm{P}=0.02)$, but not with persistent $\mathrm{OH}(\mathrm{P}=0.48)$ (Tables 3 and 4).

\section{Discussion}

It has been appreciated that there may be significant differences between CBP and PBP. A number of studies showed measurement of the $\mathrm{BP}$ in aorta or $\mathrm{CBP}$ was related to major $\mathrm{CV}$ events $[7,8]$. Indirect reading of CBP can be measured non-invasively by SphygomoCor system. One study showed that orthostatic symptoms are better reflected by CBP as measured non-invasively in the carotids. When carotid and brachial BPs were measured simultaneously using cuff-oscillometric and tonometric methods, the orthostatic decline in BP was more prominent in the carotid artery. In that study, while nine subjects were diagnosed with $\mathrm{OH}$ via the brachial $\mathrm{BP}, 21$ subjects were diagnosed by carotid $\mathrm{BP}(\mathrm{P}<0.001)$, and these results indicated that evaluation of $\mathrm{OH}$ by brachial $\mathrm{BP}$ may underestimate $\mathrm{OH}$ [9]. These study results indicated that the evaluation of orthostatic changes with CBP may be better. However, in our study, CBP can similarly identify $\mathrm{OH}$ like $\mathrm{PBP}$, and there was moderate agreement between transient $\mathrm{OH}$ at any time $(\mathrm{kappa}=0.56)$ and with persistent $\mathrm{OH}(\mathrm{kappa}=0.68)$. Alteration of the reflection pressure wave could be one of the underlying mechanisms of $\mathrm{OH}$ in the central artery. We also saw in this study a significant association with AP only with central persistent $\mathrm{OH}$, but not with other indices. $\mathrm{OH} / \mathrm{PH}$ can increase the risk for multiple conditions, such as falls, which continue to be a major problem in healthcare causing extended hospital days, fractures, head injuries, and even death. By diagnosing $\mathrm{OH} / \mathrm{PH}$ accurately, falls can be prevented by following non-pharmacological $\mathrm{OH} /$ $\mathrm{PH}$ precautions and modifying relevant risk factors [10]. Some prospective studies did not show an association between $\mathrm{OH}$ and falls $[11,12]$. But in this study transient $\mathrm{OH}$ was associated with past falls but not seen with persistent $\mathrm{OH}$, and this could be related to the small sample size of this study. 
Table 3. Relationship Between Transient Orthostatic Hypotension $(\mathrm{OH})^{\mathrm{a}}$, Cardiovascular and Fall-Related Outcomes by Peripheral and Central Blood Pressures

\begin{tabular}{|c|c|c|c|c|}
\hline \multirow{3}{*}{ Variables } & \multicolumn{4}{|c|}{ Transient $\mathrm{OH}$} \\
\hline & \multicolumn{2}{|c|}{ Peripheral blood pressure, mean (SD) or no. (\%) } & \multicolumn{2}{|c|}{ Central blood pressure, mean (SD) or no. $(\%)$} \\
\hline & No $(n=49)$ & Yes $(n=22)$ & No $(n=52)$ & Yes $(n=19)$ \\
\hline Central AI (\%) & $29.3(11.7)$ & $30.2(11.0)$ & $28.8(11.3)$ & $31.8(11.9)$ \\
\hline Symptoms of $\mathrm{OH}$ & $21(42.9 \%)$ & $9(40.9 \%)$ & $25(48.1 \%)$ & $5(26.3 \%)$ \\
\hline History of falls & $18(36.7 \%)$ & $5(22.7 \%)$ & $21(40.4 \%)$ & $2(10.5 \%)$ \\
\hline Hypertension & $33(67.3 \%)$ & $18(81.8 \%)$ & $34(65.4 \%)$ & $17(89.5 \%) \dagger$ \\
\hline Coronary artery disease & $8(16.3 \%)$ & $3(13.6 \%)$ & $8(15.4 \%)$ & $3(15.8 \%)$ \\
\hline Stroke & $7(14.3 \%)$ & $2(9.1 \%)$ & $6(11.5 \%)$ & $3(15.8 \%)$ \\
\hline Heart failure & $3(6.1 \%)$ & $1(4.5 \%)$ & $2(3.8 \%)$ & $2(10.5 \%)$ \\
\hline CKD & $1(2.0 \%)$ & $2(9.1 \%)$ & $1(1.9 \%)$ & $2(10.5 \%)$ \\
\hline
\end{tabular}

a. Orthostatic hypotension as measured and present at 1 or 3 or 6 min of standing. $\nmid P<0.05$.

One of the strengths of this study is that this is the first cohort study to measure $\mathrm{OH}$ using $\mathrm{CBP}$. In this study, we have analyzed transient $\mathrm{OH}$, persistent $\mathrm{OH}$, as well as early and delayed $\mathrm{OH}$. Limitations of this study include its cross-sectional nature, which shows only association and not causation, and the small sample size. Additionally, the selection of the $20 \mathrm{~mm}$ $\mathrm{Hg} / 10 \mathrm{~mm} \mathrm{Hg}$ drop as the threshold for defining $\mathrm{OH}$ for CBP based on the consensus criteria for PBP measurement may still not be an optimal cut-off for CBP.

\section{Clinical significance}

The traditional diagnostic criteria for $\mathrm{OH} / \mathrm{PH}$ with $\mathrm{PBP}$ do not

Table 4. Relationship Between Persistent Orthostatic Hypotension $(\mathrm{OH})^{\mathrm{a}}$, Cardiovascular and Fall-Related Outcomes by Peripheral and Central Blood Pressures

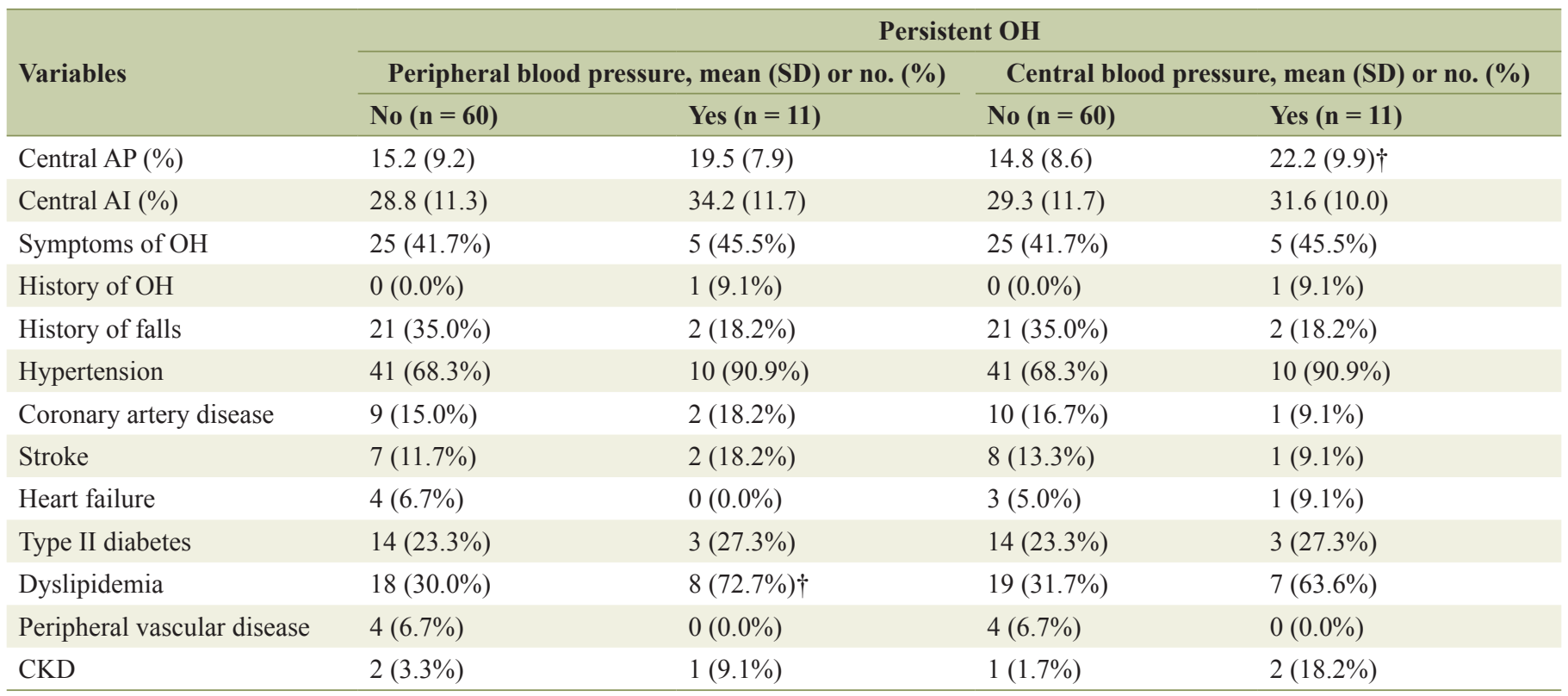

a Orthostatic hypotension as measured and present at 1,3 , and 6 min of standing. $\dagger P<0.05$. 
cause symptoms or adverse outcomes in all subjects (asymptomatic $\mathrm{OH}$ ). This study assessed whether identifying the $\mathrm{OH} /$ $\mathrm{PH}$ using $\mathrm{CBP}$, would have important implications for future diagnosis and management of $\mathrm{OH} / \mathrm{PH}$ in patients. But this study showed that CBP can similarly identify OH like PBP. Future studies with a large sample size are needed to define appropriate cut-offs and also to validate central $\mathrm{OH}$ in clinical practice.

\section{Funding}

Summer Student Funding provided by a Davis and Beatrice Reidford Research Scholarship.

\section{Conflict of Interest}

None.

\section{Author Contributions}

Kannayiram Alagiakrishnan: study design, planning, implementation, leading the study group and writing the manuscript. Raj Padwal and Peter Hamilton: study design, planning, helping with recruitment process, involvement in the preparation of the manuscript and medical supervision of study subjects if necessary. Ambikaipakan Senthilselvan: statistical analysis and presentation of results in the manuscript. Ruojin $\mathrm{Bu}$ (summer student): collecting the data from recruited subjects, entering the data in spreadsheet and participation in the preparation of manuscript.

\section{References}

1. Sharman J, Stowasser M, Fassett R, Marwick T, Franklin $\mathrm{S}$. Central blood pressure measurement may improve risk stratification. J Hum Hypertens. 2008;22(12):838-844.

2. Feldstein C, Weder AB. Orthostatic hypotension: a common, serious and underrecognized problem in hospital- ized patients. J Am Soc Hypertens. 2012;6(1):27-39.

3. Consensus statement on the definition of orthostatic hypotension, pure autonomic failure, and multiple system atrophy. The Consensus Committee of the American Autonomic Society and the American Academy of Neurology. Neurology. 1996;46(5):1470.

4. Streeten DH, Anderson GH, Jr. Delayed orthostatic intolerance. Arch Intern Med. 1992;152(5):1066-1072.

5. Benvenuto LJ, Krakoff LR. Morbidity and mortality of orthostatic hypotension: implications for management of cardiovascular disease. Am J Hypertens. 2011;24(2):135144.

6. Pauca AL, O’Rourke MF, Kon ND. Prospective evaluation of a method for estimating ascending aortic pressure from the radial artery pressure waveform. Hypertension. 2001;38(4):932-937.

7. Vlachopoulos C, Aznaouridis K, O’Rourke MF, Safar ME, Baou K, Stefanadis C. Prediction of cardiovascular events and all-cause mortality with central haemodynamics: a systematic review and meta-analysis. Eur Heart J. 2010;31(15):1865-1871.

8. Roman MJ, Devereux RB, Kizer JR, Lee ET, Galloway JM, Ali T, Umans JG, et al. Central pressure more strongly relates to vascular disease and outcome than does brachial pressure: the Strong Heart Study. Hypertension. 2007;50(1):197-203.

9. Tabara Y, Nakura J, Kondo I, Miki T, Kohara K. Orthostatic systolic hypotension and the reflection pressure wave. Hypertens Res. 2005;28(6):537-543.

10. Chang JT, Morton SC, Rubenstein LZ, Mojica WA, Maglione M, Suttorp MJ, Roth EA, et al. Interventions for the prevention of falls in older adults: systematic review and meta-analysis of randomised clinical trials. BMJ. 2004;328(7441):680.

11. Graafmans WC, Ooms ME, Hofstee HM, Bezemer PD, Bouter LM, Lips P. Falls in the elderly: a prospective study of risk factors and risk profiles. Am J Epidemiol. 1996;143(11):1129-1136.

12. McCarthy F, Fan CW, Kearney PM, Walsh C, Kenney RA. What is the evidence for cardiovascular disorders as a risk factor for non-syncopal falls? Scope for future research. Eur Geriatr Med. 2010;1:244-251. 